\title{
A Method for Optimizing Train Diagram of High-speed Railway with Soft
}

\section{Time-window}

\author{
Wei Zeng ${ }^{\mathrm{a}}$, Xingchen Zhang ${ }^{\mathrm{b}}$, Xinmiao Zhao ${ }^{\mathrm{c}}$ \\ MOE Key Laboratory for Urban Transportation Complex Systems Theory and Technology, Beijing \\ Jiaotong University, Beijing 100044

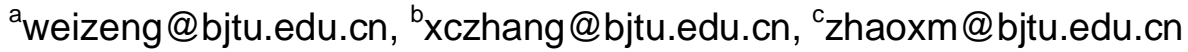

Key words: High-speed railway; Soft time-window; Conflict resolution; Simulated annealing algorithm

\begin{abstract}
This paper studies optimization of train diagram with different speed of high-speed railways, and introduces soft time window to construct the optimization model of train diagram, aiming at minimizing the difference between the arrival and departure time of the trains and the expectation of passengers with the constraints of reasonable overtakes. A global optimization heuristic algorithm is designed with the combination of strategies on conflict resolution of the lines and simulated annealing, and the case study proves the effectiveness of the optimization method and shows the convergence of the algorithm.
\end{abstract}

\section{Introduction}

Modeling of train diagram is determining the traits of the trains on the routes and the relationship among the trains, which are finally displayed by train timetable.

Many researchers have studied deeply on optimization of train diagram, such as literature [1-2] proposed a hierarchical of designing diagram by layer, the former used the method of Lagrangian relaxation to decompose the original problem, then the sub-problems were solved by the alghrithm; the latter constructed a layered superposed model which was solved by an improved genetic algorithm; literature[3] proposed a optimization method of temporal window scroll local to organically combine local optimization and global optimization; Literature [4-5] proposed an method based on ordinal optimization, the former used the method of relaxation to resolute conflict; the latter introduced the method of ordinal optimization to improve computational efficiency.

The existing studies mostly macro studied train diagram, aiming at minimizing the travel time without strict constraints on the arrival and departure time of trains, which is considered in this paper by ensuring them in a expected time domain as much as possible to improve the service quality.

\section{Problem description}

As the high-speed trains can take overtake the low-speed trains, this paper studies the problem of arranging the trains under the constraints of different safety intervals and reasonable overtaking, with the given departure time domain on originating station of high-speed train and the arrival time domain on the next station of low-speed train. This article assumes as follows: (1) a low-speed train can't be overtaken more than twice at one station; (2) trains run at a uniform speed in the section. 


\section{Modeling methodology}

Mathematical formulation. Parameters in this paper are defined as follows:

$T$ : operation time of train diagram; $H$ : the train set running on the high-speed railway line $L$, $H=H_{1} \cup H_{2} ; H_{1}$ : train set of high-speed; $H_{2}$ : train set of low-speed; $N$ : number of high-speed train; $M:$ number of low-speed train; $S:$ station set of line $L ; S=\{1,2, \ldots, u, u+1, \ldots, U\} ; r_{j}^{u}:$ running

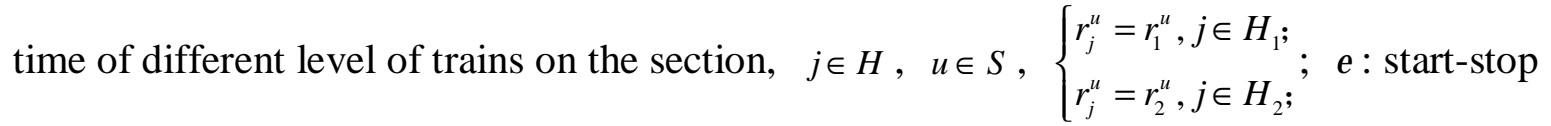
additional time; $s_{i}$ : stop time at stations; $I_{\min }^{d}:$ safety track interval; $I_{\max }^{d}:$ maximum interval of successive departure; $I_{\min }^{a}:$ minimum interval of successive arrival; $I_{\min }^{a, d}:$ minimum interval between departure and arrival; $h t_{j}^{e}$ : earliest time of high-speed railway on the origin station; $h t_{j}^{l}$ : latest time of high-speed railway on the origin station, $j \in H_{1} ; c t_{i}^{e}$ : earliest time of low-speed railway on the origin station; $c t_{i}^{l}$ : latest time of high-speed railway on the origin station, $i \in H_{2}$; $T D_{j}^{u}$ : departure time of $\operatorname{train} j$ at station $u, j \in H, u \in S ; T A_{j}^{u}$ : arrival time of $\operatorname{train} j$ at station $u, j \in H, u \in S$.

Modeling the total time deviation. Soft time window is introduced to describe the problem, which is defined as follows:

$$
\begin{aligned}
& f\left(T D_{j}^{u}\right)=\left\{\begin{array}{l}
h t_{j}^{e}-T D_{j}^{u}, T D_{j}^{u}<h t_{j}^{e} \\
0, h t_{j}^{e} \leq T D_{j}^{u}<h t_{j}^{l} \quad, u=1, \quad j \in H a \\
T D_{j}^{u}-h t_{j}^{l}, T D_{j}^{u}>h t_{j}^{l}
\end{array}\right. \\
& f\left(T A_{i}^{u}\right)=\left\{\begin{array}{l}
c t_{i}^{e}-T A_{i}^{u}, T A_{i}^{u}<c t_{i}^{e} \\
0, c t_{i}^{e} \leq T A_{i}^{u}<c t_{i}^{l} \quad, u=2, \quad i \in H b \\
T A_{i}^{u}-c t_{i}^{l}, T A_{i}^{u}>c t_{i}^{l}
\end{array}\right.
\end{aligned}
$$

The fare is 0 when the departure and arrival time is in the expected domain. Function(1) describes the penalty function when departure time of high-speed trains aren't in the domain; function(2) describes the penalty function when arrival time of high-speed trains aren't in the domain.

The difference value of the actual departures and arrivals with the time domain can be described as:

$$
\min o b j=\sum_{j=1}^{j=N} f\left(T D_{j}^{u}\right)+\sum_{i=1}^{j=M} f\left(T A_{i}^{u+1}\right), u=1, j \in H a, i \in H b
$$

Constraints formulation. Trains have to subject to the following constraints to ensure safety and operational efficiency because of the high concentration of high-speed trains in operation.

$$
\begin{array}{ccl}
T A_{j}^{u+1}-T D_{j}^{u}=r_{j}^{u} & j \in H, & u \in S \\
s_{j}^{u}=T A_{j}^{u}-T D_{j}^{u} \geq s_{j} & j \in H, & u \in S \\
T D_{j}^{u}-T D_{j+1}^{u} \geq I_{\min }^{d} & j \in H, & u \in S \\
T A_{j}^{u}-T A_{j+1}^{u} \geq I_{\min }^{a} & j \in H, & u \in S \\
T A_{j}^{u}-T D_{j+1}^{u} \geq I_{\min }^{a, d} & j \in H, & u \in S \\
\left(T A_{j-1}^{u+1}-T A_{j}^{u+1}\right)+\left(T D_{j}^{u}-T D_{j-1}^{u}\right)>r_{j-1}^{u}-r_{j}^{u} \quad j \in H a, \quad j-1 \in H b, \quad u \in S
\end{array}
$$

In which, the constraints are respectively on running time on sections, stop time at stations, safety of train track, interval of concessive arrivals, time domain of departure and arrivals and suitable overtaking. 


\section{Heuristic algorithm design}

The basic idea of the algorithm: conflict resolution is designed, then simulated annealing algorithm is used for global optimization of train diagram.

Conflict resolution strategy of train diagram. Conflict resolution is used to ensure the lines satisfy the constraints of the model.

1) Conflict resolution in sections. When the preceding train is a low-speed train and the following train is a high-speed train, there may be a conflict in the section which needs to be adjusted:

$$
\begin{gathered}
X_{1}=T D_{j}^{u}-T D_{j^{\prime}}^{u}+I_{\text {min }}^{d} \\
X_{0}=T A_{j^{\prime}}^{u}-T A_{j}^{u}+I_{\text {min }}^{a}
\end{gathered}
$$

Formula (10) indicates the left margin when moving the line at station $u$; formula (11) indicates the right margin when moving the line at station $u+1$. The smaller one is the range of movement: $X=\min \left(X_{0}, X_{1}\right)$. If the moved lines can meet the constraints on departure and arrival times, the conflict resolution succeeds; otherwise, conflict resolution is performed on the interval of working at the station.

2) Conflict resolution on stations. Conflict resolution on stations refers to when the trains can't satisfy the interval constraints, the lines can be moved to satisfy the constraints of work at stations:

$$
\begin{aligned}
& Y_{1}=I_{d}-\left(T D_{j}^{u}-T D_{j^{\prime}}^{u}\right) \\
& Y_{2}=I_{a, d}-\left(T D_{j}^{u}-T D_{j^{\prime}}^{u}\right) \\
& Y_{3}=I_{a, d}-\left(T A_{j}^{u}-T A_{j^{\prime}}^{u}\right)
\end{aligned}
$$

Formula (12) describes the range of movement when train $j$ and the preceding train $j^{\prime}$ can't meet the safety tracking interval at station $u$; Formula (13) describes the range of movement when train $j$ and the preceding train $j^{\prime}$ can't meet the successive arrival interval at station $u$; Formula (14) describes the range of movement when train $j$ and the preceding train $j^{\prime}$ can't meet the interval between arrival and departure at station $u$;

A global optimization algorithm based on simulated annealing algorithm. This paper designs a global optimization algorithm combined the principle of adjustment for train lines with the base of simulated annealing algorithm, and the steps are as follows:

Step 1: Initialization.

Step 1.1: Input the parameters $N 、 N_{1} 、 N_{2} 、 U$, then read $\left[h t_{j}^{e}, h t_{j}^{l}\right]$ and $\left[c t_{i}^{e}, c t_{i}^{l}\right]$ to transfer the arrival time of low-speed train at the next station into originating time domain;

Step 1.2: Set the control parameters of simulated annealing $T_{0} 、 T_{d} 、 P 、 Q$, and $T=T_{0}, p=0$, $q=0$.

Step 1.3: Calculate arrival and departure times of each train at each station, $T D_{j}^{1}=j^{*} I_{\max }^{d}$, $\left\{\begin{array}{l}T A_{j}^{u}=T D_{j}^{u-1}+p r_{j}^{u-1}+t_{d}+t_{a} \\ T D_{j}^{u}=T A_{j}^{u}+s_{j}\end{array} \quad, \quad\right.$ to $\quad$ obtain the time series of train $j$ : $N T_{j}=\left(T D_{j}^{1}, T A_{j}^{2}, T D_{j}^{2}, \ldots, T A_{j}^{M-1}, T D_{j}^{M-1}, T A_{j}^{M}\right)$;

Step 1.4: Detect and update time series of each train, and add them to train diagram to generate original timetable $F T$;

Step 2: Regard $F T$ as the initial solution of simulated annealing algorithm, and calculate its objective as the current optimal solution, $F T_{b}=F T$;

Step 3: Construct solution field: generate a integer $z$ randomly from $[1, N]$ as the number of the train to be adjusted and record the train's departure time $T D_{z}^{1}$;

Determine whether the train departure time $T D_{z}^{1}$ is in its corresponding domain: if $h t_{z}^{e} \leq T D_{z}^{1} \leq h t_{z}^{l}$, then turn Step6; if $T D_{z}^{1} \geq h t_{j}^{l}$, then $\left(T D_{z}^{1}\right)^{\prime}=T D_{z}^{1}-h t_{z}^{l}-\operatorname{random}\left(0, h t_{z}^{l}-h t_{z}^{e}\right)$,Turn Step4; 
if $T D_{z}^{1} \leq h t_{z}^{e}$, then $\left(T D_{z}^{1}\right)^{\prime}=h t_{z}^{l}-T D_{z}^{1}+\operatorname{random}\left(0, h t_{z}^{l}-h t_{z}^{e}\right)$. Update the time series of train $z$ and the following train, and update solution field as $F T^{\prime}$;

Step 4: Detect and resolute conflict to generate train diagram, $F T_{u}=F T^{\prime \prime}$; otherwise, $F T_{u}=F T^{\prime}$.

Step 5: Metropolis test criteria: calculated $\Delta o b j=o b j\left(F T_{u}\right)-o b j\left(F T_{b}\right)$, if $\Delta o b j<0, \quad F T_{b}=F T_{u}$ and the current train diagram is accepted; otherwise, accept $F T_{u}$ with the probability of $\exp (-\Delta o b j / T)>\varepsilon$;

Step 6: Check the inner loop: if $p<P, p=p+1$, turn Step 3; otherwise, turn Step 7.

Step 7: Termination condition of the algorithm: if $q \geq Q$ or $T \leq T_{d}$, the algorithm breaks down and output the train schedule; otherwise, let the current temperature $T=\delta T, q=q+1, \quad p=0$, turn Step 3.

\section{Case study}

Parameter settings. Taking a high-speed railway as an example, on which 7 stations are located. In the research period, 16 trains originate, of which 13 trains are high-speed while 3 low-speed. The referred parameters are shown in Table 1; the pure running time of different trains on sections is shown in Table 2; the time domain of train departure time is shown in Table 3; the parameters of simulated annealing algorithm are shown in Table 4.

Table 1 Parameter identification

\begin{tabular}{|c|c|}
\hline Parameter type & Value(min) \\
\hline Additional time for starting $\left(t_{d}\right)$ & 1 \\
\hline Additional time for stopping $\left(t_{a}\right)$ & 1 \\
\hline Interval of the safe following operation $\left(I_{\min }^{d}\right)$ & 3 \\
\hline Minimum interval of the arrivals $\left(I_{\min }^{a}\right)$ & 2 \\
\hline Minimum interval of the arrival and departure $\left(I_{\min }^{a, d}\right)$ & 2 \\
\hline Stop time $\left(S_{i}\right)$ & High-speed (1) \\
\hline
\end{tabular}

Table 2 Running time in the section

\begin{tabular}{ccc}
\hline Section & High-speed train(min) & Low-speed train(min) \\
\hline $1-2$ & 8 & 10 \\
$2-3$ & 12 & 15 \\
$3-4$ & 14 & 16 \\
\hline $4-5$ & 10 & 12 \\
$5-6$ & 8 & 10 \\
$6-7$ & 6 & 7 \\
\hline
\end{tabular}

Table 3 The earliest and latest departure time of the train

\begin{tabular}{cccccccc}
\hline $\begin{array}{c}\text { Train } \\
\text { speed }\end{array}$ & $\begin{array}{c}\text { Train } \\
\text { number }\end{array}$ & $\begin{array}{c}\text { Earliest } \\
\text { departure }\end{array}$ & $\begin{array}{c}\text { Latest } \\
\text { departure }\end{array}$ & $\begin{array}{c}\text { Train } \\
\text { speed }\end{array}$ & $\begin{array}{c}\text { Train } \\
\text { number }\end{array}$ & $\begin{array}{c}\text { Earliest } \\
\text { departure }\end{array}$ & $\begin{array}{c}\text { Latest } \\
\text { departure }\end{array}$ \\
\hline high & 1 & $7: 01$ & $7: 08$ & high & 9 & $8: 05$ & $8: 12$ \\
high & 2 & $7: 09$ & $7: 16$ & low & 10 & $8: 13$ & $8: 20$ \\
high & 3 & $7: 17$ & $7: 24$ & high & 11 & $8: 21$ & $8: 28$ \\
high & 4 & $7: 25$ & $7: 32$ & high & 12 & $8: 29$ & $8: 36$ \\
low & 5 & $7: 33$ & $7: 40$ & high & 13 & $8: 37$ & $8: 44$ \\
high & 6 & $7: 41$ & $7: 48$ & high & 14 & $8: 45$ & $8: 52$ \\
high & 7 & $7: 49$ & $7: 56$ & low & 15 & $8: 53$ & $9: 00$ \\
high & 8 & $7: 57$ & $8: 04$ & high & 16 & $9: 00$ & $9: 00$ \\
\hline
\end{tabular}


Table 4 Parameters of simulated annealing algorithm

\begin{tabular}{cc}
\hline Parameter & Value \\
\hline Initial temperature $\left(T_{0}\right)$ & $90^{\circ} \mathrm{C}$ \\
Stop tempertature $\left(T_{d}\right)$ & $30^{\circ} \mathrm{C}$ \\
The number of inner cycles $(P)$ & 30 \\
The number of external cycles $(Q)$ & 80 \\
Metropolis parament $(\varepsilon)$ & 0.001 \\
Coefficient of temperature reduction $(\delta)$ & 0.9 \\
\hline
\end{tabular}

Result analysis. Numerical example was conducted on a computer with the following configuration: 4GB Memory, Windows 7 operating system, and the processor CPU is Inter Core i5 with $1.8 \mathrm{GHz}$. The optimal train schedule was computed by $\mathrm{VC}++$, and the objective function is zero, with 12.5-min running time. The best departure time of the train on origin station is shown in Table 5.

Table 5 The optimal train departure time

\begin{tabular}{cccccccc}
\hline $\begin{array}{c}\text { Train } \\
\text { number }\end{array}$ & $\begin{array}{c}\text { Departure } \\
\text { time }\end{array}$ & $\begin{array}{c}\text { Time } \\
\text { region }\end{array}$ & Deviation & $\begin{array}{c}\text { Train } \\
\text { number }\end{array}$ & $\begin{array}{c}\text { Departure } \\
\text { time }\end{array}$ & $\begin{array}{c}\text { Time } \\
\text { region }\end{array}$ & Deviation \\
\hline 1 & $7: 07$ & $\mathrm{Y}$ & 0 & 9 & $8: 08$ & $\mathrm{Y}$ & 0 \\
2 & $7: 14$ & $\mathrm{Y}$ & 0 & 10 & $8: 15$ & $\mathrm{Y}$ & 0 \\
3 & $7: 21$ & $\mathrm{Y}$ & 0 & 11 & $8: 24$ & $\mathrm{Y}$ & 0 \\
4 & $7: 28$ & $\mathrm{Y}$ & 0 & 12 & $9: 31$ & $\mathrm{Y}$ & 0 \\
5 & $7: 35$ & $\mathrm{Y}$ & 0 & 13 & $9: 40$ & $\mathrm{Y}$ & 0 \\
6 & $7: 43$ & $\mathrm{Y}$ & 0 & 14 & $9: 48$ & $\mathrm{Y}$ & 0 \\
7 & $7: 49$ & $\mathrm{Y}$ & 0 & 15 & $8: 55$ & $\mathrm{Y}$ & 0 \\
8 & $7: 59$ & $\mathrm{Y}$ & 0 & 16 & $9: 00$ & $\mathrm{Y}$ & 0 \\
\hline
\end{tabular}

Figure 1 compares initial solution and optimal solutions of the example, which shows the goal of the former is 45 while the latter 0 , meaning that the lines of optimal solution all meet the expected time domain.

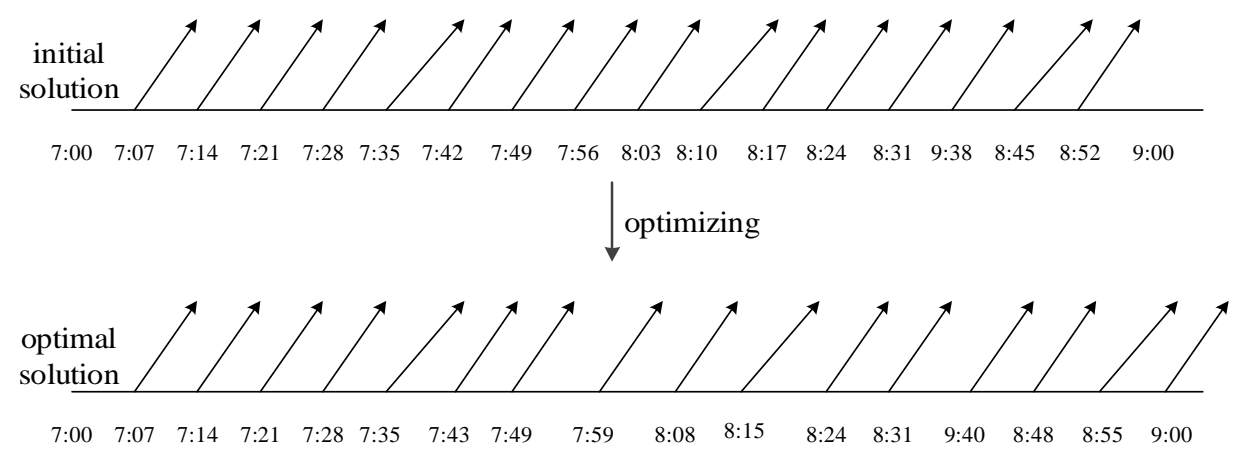

Fig 1 Comparison between initial solution and optimal solution

As can be seen from the results, due to the difference in speed between high-speed trains and low-speed trains, low-speed train 5 is overtaken by high-speed train 6 and7 at station 3 and 5; low-speed train 10 is overtaken by high-speed train 11 and 12 at station 3 and 5 ; low-speed train 15 is overtaken by high-speed train 16 at station 3 and 5 . Therefore, the overtaking meets the rule of high-speed trains could overtake low-speed trains; and the trains are overtaken by one or two trains, which meet the assumption. 


\section{Conclusions}

This paper introduced soft time windows of departure and arrival time to optimal high-speed train diagram, an optimization model was built with constraints of overtaking. The results show that the goal decreased from 45 to 0 , ensuring the departure and arrival time of all trains in expected domain, and the overtaking of trains meet the assumptions.

\section{Acknowledgements}

This work was financially supported by National Natural Science Foundation of China(71131001,71390332). The authors also thank the anonymous reviewers and the editor for their suggestions to improve this paper.

\section{References}

[1]. J.E. Cury, F.A.C. Gomide and M.J. Mendes. A methodogy for generation off optimal schedules far an underground technique[J]. IEEE Transactions on Robotics and Automation, 1994, 10(2): 99-111.

[2]. H. XU, J.J. MA and J.C. LONG. Research on the Model and Algorithm of the Train Working Diagram of Dedicated Passenger Line[J]. Journal of the China Railway Societ, 2007, 29(2): 17.

[3]. Q.Y. PENG, M.L. YANG and S.Q. NI. A System of Making Train Working Graph on Single-Track Lines with Computer[J]. Journal of Southwest Jiaotong University, 1995, 30(5): 537-542.

[4]. W.L. ZHOU, F. SHI and Y. CHEN. A Method for Drawing Train Diagram of Deticated Passenger Line Based on Fixed Order Optimization[J]. Journal of the China Railway Societ, 2010, 32(1): 1-7.

[5]. Y.J. CHEN, L.S. ZHOU. Study on Train Operation Adjustment Algorithm Based on Ordinal Optimization[J]. Journal of the China Railway Societ, 2010, 32(3): 1-8.

[6]. G. Caimi, M. Fuchsberger and M. Laumanns. Periodic railway timetabling with event flexibility[J]. Networks, 2011, 57(1): 3-18.

[7]. J.J. BAO, P.J. XU. Research on Equilibrium of High-speed Railway Train Working Diagram[J]. Railway Transport and Economy, 2012, 34(5): 21-26. 